\title{
Role of genomic architecture in the expression dynamics of long noncoding RNAs during differentiation of human neuroblastoma cells
}

\author{
Arsen O Batagov ${ }^{1 \dagger}$, Aliaksandr A Yarmishyn ${ }^{1 \dagger}$, Piroon Jenjaroenpun ${ }^{1}$, Jovina Z Tan', Yuichiro Nishida², \\ Igor $\mathrm{V}$ Kurochkin ${ }^{1 *}$
}

From Asia Pacific Bioinformatics Network (APBioNet) Twelfth International Conference on Bioinformatics (InCoB2013)

Taicang China. 20-22 September 2013

\begin{abstract}
Background: Mammalian genomes are extensively transcribed producing thousands of long non-protein-coding RNAs (IncRNAs). The biological significance and function of the vast majority of IncRNAs remain unclear. Recent studies have implicated several IncRNAs as playing important roles in embryonic development and cancer progression. LncRNAs are characterized with different genomic architectures in relationship with their associated protein-coding genes. Our study aimed at bridging IncRNA architecture with dynamical patterns of their expression using differentiating human neuroblastoma cells model.

Results: LncRNA expression was studied in a 120-hours timecourse of differentiation of human neuroblastoma SHSY5Y cells into neurons upon treatment with retinoic acid (RA), the compound used for the treatment of neuroblastoma. A custom microarray chip was utilized to interrogate expression levels of 9,267 IncRNAs in the course of differentiation. We categorized IncRNAs into 19 architecture classes according to their position relatively to protein-coding genes. For each architecture class, dynamics of expression of IncRNAs was studied in association with their protein-coding partners. It allowed us to demonstrate positive correlation of IncRNAs with their associated protein-coding genes at bidirectional promoters and for sense-antisense transcript pairs. In contrast, IncRNAs located in the introns and downstream of the protein-coding genes were characterized with negative correlation modes. We further classified the IncRNAs by the temporal patterns of their expression dynamics. We found that intronic and bidirectional promoter architectures are associated with rapid RA-dependent induction or repression of the corresponding IncRNAs, followed by their constant expression. At the same time, IncRNAs expressed downstream of protein-coding genes are characterized by rapid induction, followed by transcriptional repression. Quantitative RT-PCR analysis confirmed the discovered functional modes for several selected IncRNAs associated with proteins involved in cancer and embryonic development.

Conclusions: This is the first report detailing dynamical changes of multiple IncRNAs during RA-induced neuroblastoma differentiation. Integration of genomic and transcriptomic levels of information allowed us to demonstrate specific behavior of IncRNAs organized in different genomic architectures. This study also provides a list of IncRNAs with possible roles in neuroblastoma.
\end{abstract}

\footnotetext{
* Correspondence: igork@bii.a-star.edu.sg

+ Contributed equally

'Department of Genome and Gene Expression Data Analysis, Bioinformatics

Institute, 30 Biopolis Str, Singapore, 138671

Full list of author information is available at the end of the article
} 


\section{Background}

The transcriptome analysis studies of the past decade revealed that only a small proportion of mammalian genomes (less than $2 \%$ ) is transcribed into protein coding mRNAs $[1,2]$. The remaining non-coding part of the genome on the other hand is extensively transcribed into various classes of non-coding RNAs. Among them small regulatory RNAs, such as microRNAs and siRNAs, have been extensively studied. However, the largest fraction of the non-coding transcriptome is represented by long non-coding RNAs (lncRNAs), which are defined as transcripts having size larger than 200 nucleotides [3,4]. This vast class of non-coding RNAs still remains poorly understood and its functionality continues to be a subject of debate. However, evidence is growing that many lncRNAs are important functional molecules involved in various regulatory processes. The functional lncRNAs demonstrate precise spatiotemporal patterns of expression and often exhibit specific cellular localization [5-8]. So far, lncRNAs have been shown to be associated with various biological and pathological processes, such as cell differentiation [9], embryonic development [10], immune response [11], and cancer [12]. Several insights have been gained into molecular mechanisms of lncRNA activity, specifically some lncRNAs have been shown to regulate gene expression by chromatin remodeling [13], modulation of transcription factors [14,15], translation [16], and RNA stability [17]. LncRNA genes are often arranged into complex transcriptional loci with the protein coding genes, from which they are expressed in a coordinated fashion $[6,18,19]$. Such complex loci may include overlapping architecture, such as cis-antisense, intronic, bidirectional, as well as non-overlapping with genes located in their close vicinity. Some lncRNA genes associated with protein-coding genes on genomic level encode lncRNAs cooperating with proteins on the transcriptome and proteome levels. A number of studies have demonstrated functional relationship between lncRNAs and their associated protein coding genes [15,20-22]. Several recent reports focused on predicting functions of lncRNAs from their co-localization with protein coding genes applying integrated analysis of transcriptome $[5,6,19]$. The present work extends the previous studies by detailing both characterization of IncRNA genomic architecture types and their relation to dynamics of lncRNA transcripts.

We investigated expression of lncRNAs during differentiation of SH-SY5Y neuroblastoma cell line induced by retinoic acid (RA). Using our custom microarray chip, for the first time we measured the dynamics of lncRNA expression in this model system of neuronal differentiation. The most detailed of existing annotations of lncRNA genomic architecture allowed us to discriminate 19 lncRNA classes and to evaluate expression dynamics for each individual class. We integrated this data with our previous work on dynamics of protein expression measured at the same conditions to identify potential architecture-dependent regulatory mechanisms coupling expression of lncRNAs and neighboring proteins.

\section{Results \\ Classification of IncRNA genes}

LncRNAs were identified among the genes of human genome build 36 annotated in $\mathrm{H}$-Invitational database [23]. Absence of coding regions in the genes was verified using CRITICA software, a hybrid method that combines comparative analysis with statistical analysis of coding sequences [24]. The final list included 9,267 lncRNA genes (Figure 1).

The genes were further classified by their association with neighbouring protein-coding genes by genomic architecture (GA). The closest protein coding genes in sense or antisense orientation within $10 \mathrm{kbp}$ vicinity of the lncRNA genes were identified as associated with particular lncRNAs. The associated lncRNA-protein coding gene pairs were further classified by their GA into five major groups: antisense, intergenic, promoter-associated and intronic, relative to the protein-coding genes. Each group was sub-classified, yielding in total 19 classes of lncRNAprotein gene association types (Figure 2). Antisense pairs were sub-classified into embedding, exonic, head-to-head and tail-to-tail classes. Intergenic pairs were sub-classified into upstream-associated and downstream-associated. Each of these two classes was further classified by the respective intergenic distance into three subclasses: $1 \mathrm{kbp}$, $5 \mathrm{kbp}$ and $10 \mathrm{kbp}$. Being of a of particular interest, the pairs sharing bidirectional promoters were similarly subclassified into 1, 5 and $10 \mathrm{kbp}$ - distant. The exonic pairs were sub-classified into purely exonic and embedding. The latter class included cases when lncRNA genes were located within the genomic boundaries of the associated proteins and, at the same time, were overlapping with both exonic and intronic sequences. Embedding, exonic and intronic pairs were sub-classified into sense and antisense subtypes, relative to the protein-coding gene.

In total, 5,116 lncRNA genes were found to be associated with protein coding genes, according to the above criteria. Among them the fractions of intergenic, intronic, antisense and promoter-associated lncRNA genes were $49 \%, 29 \%, 15 \%$ and $7 \%$, respectively (Figure 3 ).

Surprisingly, gene ontology (GO) analysis revealed evidence that the architecture of lncRNA-protein coding gene pairs may be related to functional specialization of the proteins in these pairs. The list of significantly enriched GOs specific to certain architecture types included genes associated with cell differentiation, 


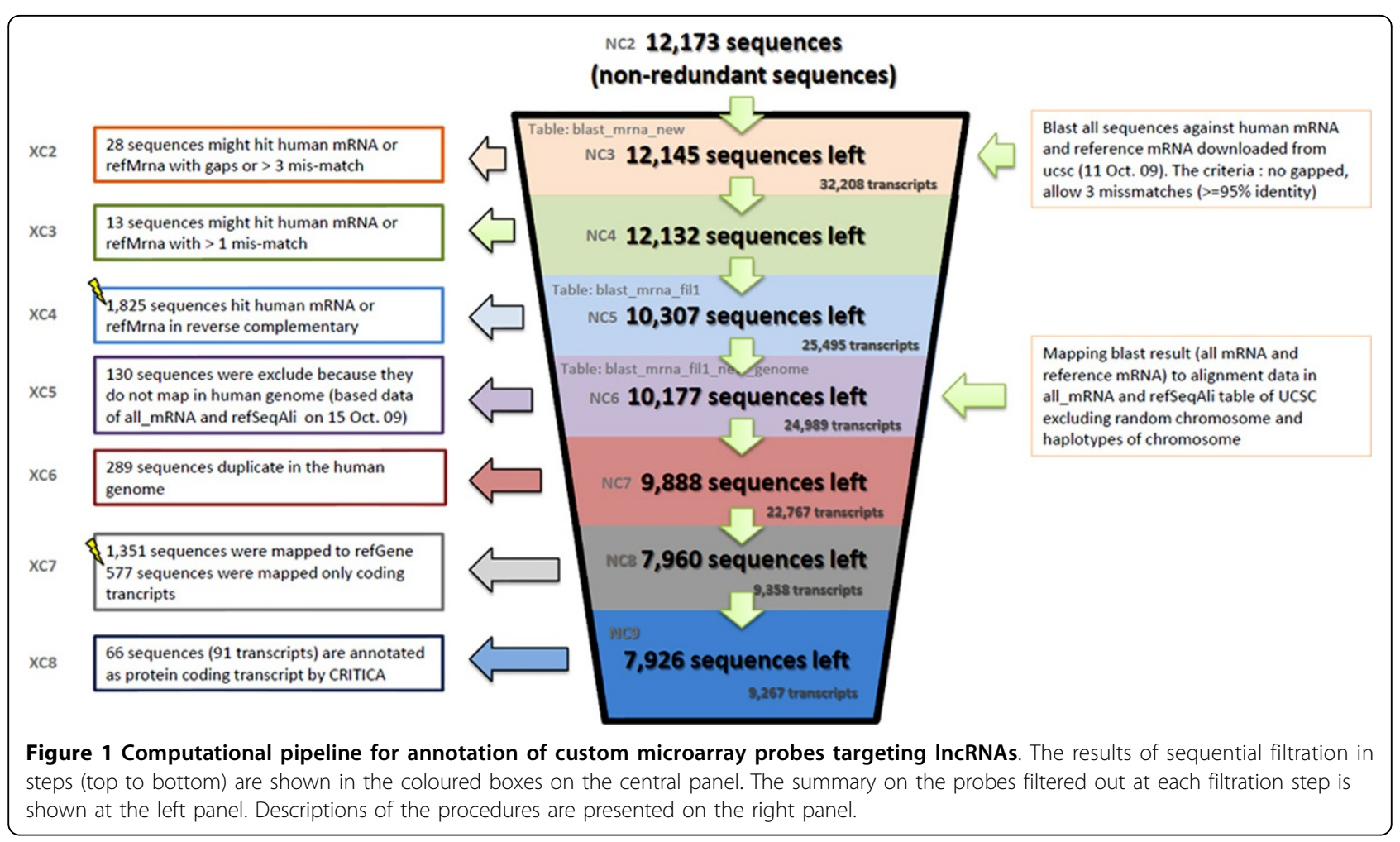

embryogenesis, signalling pathways, and cytoskeleton. For more details, see Section 1.1 of the Additional file 1.

\section{Differential expression of IncRNAs and associated protein coding genes}

To measure the expression of protein coding gene-associated lncRNAs during neuroblastoma differentiation, a custom microarray chip was designed and implemented using Agilent platform. Two biological replicates of differentiating neuroblastoma cells were screened at four time points (0, 6, 24 and 120 hours) after a single-time stimulation by RA. Confirming previous studies, the overall expression values of lncRNAs were observed to be lower than the values of mRNAs (Figure 4).

The distribution of all differentially expressed lncRNAs revealed an increase in the fraction of transcripts with antisense GA from 18\% to 22\% (Figure 5). Significant increase was observed for lncRNAs with antisense head-to-head GA relative to that with intronic $\left(P=1.61 \cdot 10^{-6}\right.$, fold enrichment $\mathrm{FE}=1.8), 1 \mathrm{kbp}$-distant bidirectional promoter $(P=0.025$, $\mathrm{FE}=1.6), 5 \mathrm{kbp}$-distant downstream-associated $(P=$ $\left.3.71 \cdot 10^{-5}, \mathrm{FE}=2.3\right), 5 \mathrm{kbp}$-distant intergenic downstream $(P=0.042, \mathrm{FE}=1.6)$, and promoter-associated $\left(P=2.91 \cdot 10^{-}\right.$ ${ }^{4}, \mathrm{FE}=2.5$ ) GAs (the calculation procedure is detailed in Satistical analysis section of Methods). Intronic antisense lncRNA were over-represented in comparison with intronic $(P=2.51 \cdot 10-6, \mathrm{FE}=1.4)$ and promoter-associated $(P=$ $0.013, \mathrm{FE}=2.0)$ lncRNAs. These observations are consistent with the well-known fact that pairs of complementary transcripts may regulate the stability of their counterparts [25].

Next, we tested whether the influence of lncRNA GA is specific to differential expression of lncRNAs or whether it might be related with the expression of the associated protein coding genes. Therefore, differentially expressed IncRNAs associated with differentially expressed protein coding genes were compared with all the differentially expressed lncRNAs, as well as with those that correlate insignificantly with the associated protein coding genes. To identify possible functional connections between the IncRNAs and their associated protein coding genes, in the cases when the expression of the lncRNA-protein pairs correlate over time, GA frequencies were evaluated separately.

Contrary to the general tendency of differentially expressed lncRNAs, the fraction of antisense GAs in positively correlating lncRNA-protein coding gene pairs decreased from $12 \%$ to $5 \%$ (Figure 5). The ratios between the individual antisense GA frequencies in all differentially expressed lncRNAs and those lncRNAs that positively correlatewith expression of protein coding genes were 4.4 for intronic, 3.5 for exonic, 2.2 for tail-to-tail and 2.1 for headto-head architectures. In comparison with intronic architecture, the differences were strongly significant (P-values ranging from $6.15 \cdot 10^{-9}$ to approximately zero with FE from 6.5 to 12.2 ). In contrast, among negatively correlating 


\begin{tabular}{|c|c|c|}
\hline Name & Schematic representation & Description \\
\hline Intronic & $\Longrightarrow$ & $\begin{array}{l}\text { IncRNA is in intronic region of protein-coding gene in the } \\
\text { same direction }\end{array}$ \\
\hline Intronic antisense & $\rightleftarrows \stackrel{\rightleftarrows}{\rightleftarrows}$ & $\begin{array}{l}\text { IncRNA is in intronic region of protein-coding gene in } \\
\text { opposite direction }\end{array}$ \\
\hline Bidirectional 1-1k & $\stackrel{\rightleftarrows}{\longrightarrow} \underset{1 \mathrm{~b} p \leq \dot{x} \leq 1 \mathrm{kbp}}{\longrightarrow}$ & $\begin{array}{l}\text { bidirectional promoter; } 5 \text { ' ends of IncRNA and protein } \\
\text { coding genes are } 1 \mathrm{bp} \text { to } 1 \mathrm{kbp} \text { apart }\end{array}$ \\
\hline Bidirectional $1 \mathrm{k}-5 \mathrm{k}$ & $\leftrightarrows \underset{1 \mathrm{kbp}<\dot{x} \leq 5 \mathrm{kbp}}{\longrightarrow}$ & $\begin{array}{l}\text { bidirectional promoter; } 5 \text { ' ends of IncRNA and protein } \\
\text { coding genes are } 1 \mathrm{kbp} \text { to } 5 \mathrm{kbp} \text { apart }\end{array}$ \\
\hline Bidirectional 5k-10k & $\stackrel{\longleftarrow}{\longrightarrow} \underset{\overline{k b p}<\dot{x} \leq 10 \mathrm{kbp}}{\longrightarrow}$ & $\begin{array}{l}\text { bidirectional promoter; } 5 \text { ' ends of IncRNA and protein } \\
\text { coding genes are } 5 \mathrm{kbp} \text { to } 10 \mathrm{kbp} \text { apart }\end{array}$ \\
\hline Intergenic downstream 1-1k & $\rightleftarrows{ }_{1 \mathrm{bp} \leq \dot{\mathrm{x}} \leq 1 \mathrm{kbp}} \leftrightarrows$ & $\begin{array}{l}\text { downstream associated; } 3 \text { ' ends of IncRNA and protein } \\
\text { coding genes are } 1 \mathrm{bp} \text { to } 1 \mathrm{kbp} \text { apart }\end{array}$ \\
\hline Intergenic downstream $1 \mathrm{k}-5 \mathrm{k}$ & $\rightleftarrows_{1 \mathrm{kbp}<\dot{x} \leq 5 \mathrm{kbp}} \leftrightarrows$ & $\begin{array}{l}\text { downstream associated; } 3 \text { ' ends of IncRNA and protein } \\
\text { coding genes are } 1 \mathrm{kbp} \text { to } 5 \mathrm{kbp} \text { apart }\end{array}$ \\
\hline Intergenic downstream $5 \mathrm{k}-10 \mathrm{k}$ & $\rightleftarrows{ }_{5 \mathrm{kbp}}<\dot{x} \leq 10 \mathrm{kbp}$ & $\begin{array}{l}\text { downstream associated; } 3 \text { ' ends of IncRNA and protein } \\
\text { coding genes are } 5 \mathrm{kbp} \text { to } 10 \mathrm{kbp} \text { apart }\end{array}$ \\
\hline Promoter associated & $\underset{x \leq 1 \mathrm{kbp} \text { or in exon } 1}{\longrightarrow}$ & $\begin{array}{l}\text { promoter associated; } 5 \text { 'end of IncRNA located between } \\
\text { putative promoter region ( } 1 \mathrm{kbp}) \text { and exon } 1 \text { of protein } \\
\text { coding gene }\end{array}$ \\
\hline Intergenic $1-1 \mathrm{k}$ left & $1 \mathrm{bp}<\dot{\mathrm{x}} \leq 1 \mathrm{kbp}$ & $\begin{array}{l}\text { intergenic; protein-coding gene located in the left side of } \\
\text { IncRNA between } 1 \mathrm{bp} \text { and } 1 \mathrm{kbp}\end{array}$ \\
\hline Intergenic $1-1 \mathrm{k}$ right & $1 \mathrm{bp}<\dot{\mathrm{x}} \leq 1 \mathrm{kbp}$ & $\begin{array}{l}\text { intergenic; protein-coding gene located in the right side of } \\
\text { IncRNA between } 1 \mathrm{bp} \text { and } 1 \mathrm{kbp}\end{array}$ \\
\hline Intergenic $1 \mathrm{k}-5 \mathrm{k}$ left & $1 \mathrm{kbp}<\dot{x} \leq 5 \mathrm{kbp}$ & $\begin{array}{l}\text { intergenic; protein-coding gene located in the left side of } \\
\text { IncRNA between } 1 \mathrm{kbp} \text { and } 5 \mathrm{kbp}\end{array}$ \\
\hline Intergenic $1 \mathrm{k}-5 \mathrm{k}$ right & $1 \mathrm{kbp}<\dot{x} \leq 5 \mathrm{kbp}$ & $\begin{array}{l}\text { intergenic; protein-coding gene located in the right side of } \\
\text { IncRNA between } 1 \mathrm{kbp} \text { and } 5 \mathrm{kbp}\end{array}$ \\
\hline Intergenic $5 \mathrm{k}-10 \mathrm{k}$ left & $5 \mathrm{kbp}<\dot{x} \leq 10 \mathrm{kbp}$ & $\begin{array}{l}\text { intergenic; protein-coding gene located in the left side of } \\
\text { IncRNA between } 5 \mathrm{kbp} \text { and } 10 \mathrm{kbp}\end{array}$ \\
\hline Intergenic $5 \mathrm{k}-10 \mathrm{k}$ right & $5 \mathrm{kbp}<\dot{\mathrm{x}} \leq 10 \mathrm{kbp}$ & $\begin{array}{l}\text { intergenic; protein-coding gene located in the right side of } \\
\text { IncRNA between } 5 \mathrm{kbp} \text { and } 10 \mathrm{kbp}\end{array}$ \\
\hline Sense-antisense head-to-head & $\longleftarrow$ & $\begin{array}{l}\text { sense-antisense transcript; type head-to-head } \\
\text { between IncRNA and protein coding genes }\end{array}$ \\
\hline Sense-antisense tail-to-tail & $\longleftarrow$ & $\begin{array}{l}\text { sense-antisense transcript; type tail-to-tail } \\
\text { between IncRNA and protein coding genes }\end{array}$ \\
\hline $\begin{array}{l}\text { Sense-antisense exon } \\
\text { embedded }\end{array}$ & $\rightleftarrows \stackrel{\longleftarrow}{\rightleftarrows}$ & $\begin{array}{l}\text { sense-antisense transcript; IncRNA completely } \\
\text { within the boundaries of exon of protein-coding gene }\end{array}$ \\
\hline Sense-antisense embedding & $\stackrel{\rightleftarrows}{\rightleftarrows}$ & $\begin{array}{l}\text { sense-antisense transcript; protein coding gene } \\
\text { completely within the boundaries of IncRNA }\end{array}$ \\
\hline \multicolumn{3}{|c|}{$\begin{array}{l}\text { Figure } 2 \text { Classification of genomic architecture classes involving gene pairs of IncRNAs and protein-coding genes. The } 19 \text { architectures } \\
\text { (in rows) describing co-localization of IncRNAs with protein-coding genes. Left column contains the name of the architecture; central column } \\
\text { contains a schematic drawing representing; right column contains a short description of the architecture. Note: the 'left' and the 'right' } \\
\text { architecture classes represent the localization of the protein-coding gene boundaries relative to the IncRNA gene boundaries on the plus DNA } \\
\text { strand, regardless of the sense or antisense orientation of both genes. }\end{array}$} \\
\hline
\end{tabular}




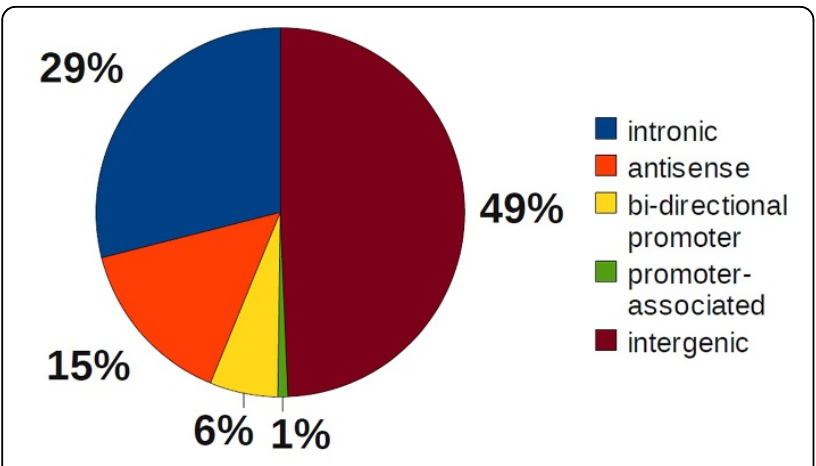

\section{6 probes for 5858 ncRNAs}

Figure 3 Frequency distribution of the genomic architecture super-classes of the IncRNAs measured by the custom microarray chip. The 19 distinct genomic architecture classes (see Figure 2) were generalized into 5 super-classes (intronic antisense bidirectional promoter, intronic and intergenic orientations) by IncRNA orientation, representing the overall topology of IncRNAprotein coding genes co-localization. Frequencies of all IncRNAs measured in the present study are given.

IncRNA-protein coding genes pairs the frequency of intronic, exonic, tail-to-tail and head-to-head antisense GAs was 6, 6.8, 6.8 and 1.7-times higher. Except for the headto-head GA, the fraction of the antisense architecture types was higher in negatively correlating lncRNAs in comparison with all differentially expressed lncRNA-protein coding pairs. The results suggest that antisense mode of architecture-dependent regulation for lncRNAs is largely negative. $\mathrm{GO}$ analysis of the protein-coding genes postitively correlating with their paired lncRNA genes did not reveal significant associations with biologcal functions specific to any given architecture.

To find whether the observed correlations between the expression levels of lncRNAs and protein coding genes are specific to certain temporal expression patterns, we analyzed their dynamics in the course of RA-induced cell differentiation.

\section{Dynamical modes of IncRNA expression}

Expression of lncRNAs and protein coding genes was analyzed at four time points in the course of RA-induced neuroblastoma cells differentiation. Dynamical patterns (modes) of lncRNA expression were discriminated: i) by the time point when a given IncRNA activation/repression is observed (Additional file 2, panel A) and ii) by the time interval of increased/decreased expression of a given lncRNA (Additional file 2, panel B). These two types of modes were named as "rate" and "magnitude", respectively. Analysis of the "rate" modes revealed that most of the studied lncRNAs were either activated or repressed already by hour six of cell differentiation and followed such trend until the end of the experiment (Figure 6). These two modes together comprised 52\% of the differentially expressed lncRNAs.

The largest increase in the frequency of mode occurrence was observed for the lncRNAs repressed by $120 \mathrm{~h}$, followed by the ones activated by $6 \mathrm{~h}$. Among the differentially expressed lncRNAs associated with the differentially expressed protein coding genes the frequencies of these modes were 1.6-times higher than those among the all differentially expressed lncRNAs. LncRNAs transiently activated at $6 \mathrm{~h}$ and permanently activated by $24 \mathrm{~h}$ were the other two classes whose frequency was higher among the

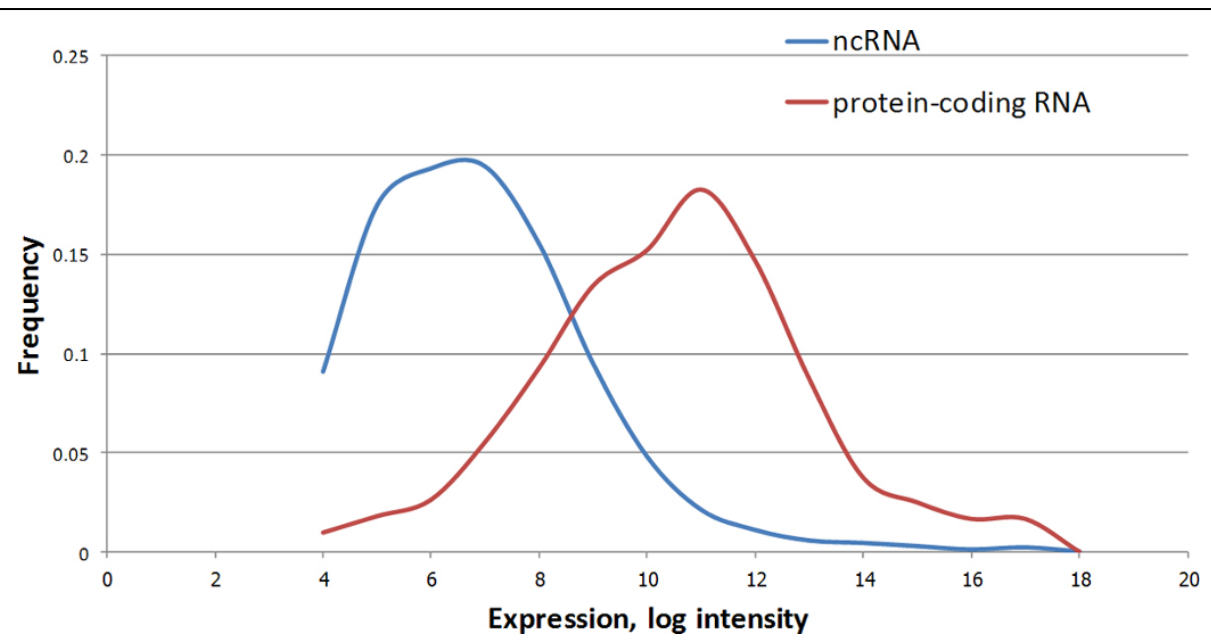

Figure 4 Distribution of expression values of IncRNAs and protein-coding genes. Smoothed densities of IncRNA (blue line) and proteincoding genes (red line) mean expression values measured in the course of RA-induced neuroblastoma cells differentiation in the present study. The data have been derived from the analysis of the custom microarray described in this study. In addition to 11,564 probes specific to IncRNAs, the array also included 728 probes matching 446 protein-coding genes. 
protein-associated differentially expressed lncRNAs, 1.3and 1.2-times, respectively. The largest frequency decrease (1.3- times) was observed among lncRNAs permanently repressed by $6 \mathrm{~h}$, followed by the ones activated by $120 \mathrm{~h}$.
The above tendencies were more clear when the protein coding gene-associated differentially expressed lncRNAs had been classified into positively and negatively correlating. For positively-correlating lncRNA genes the mode 


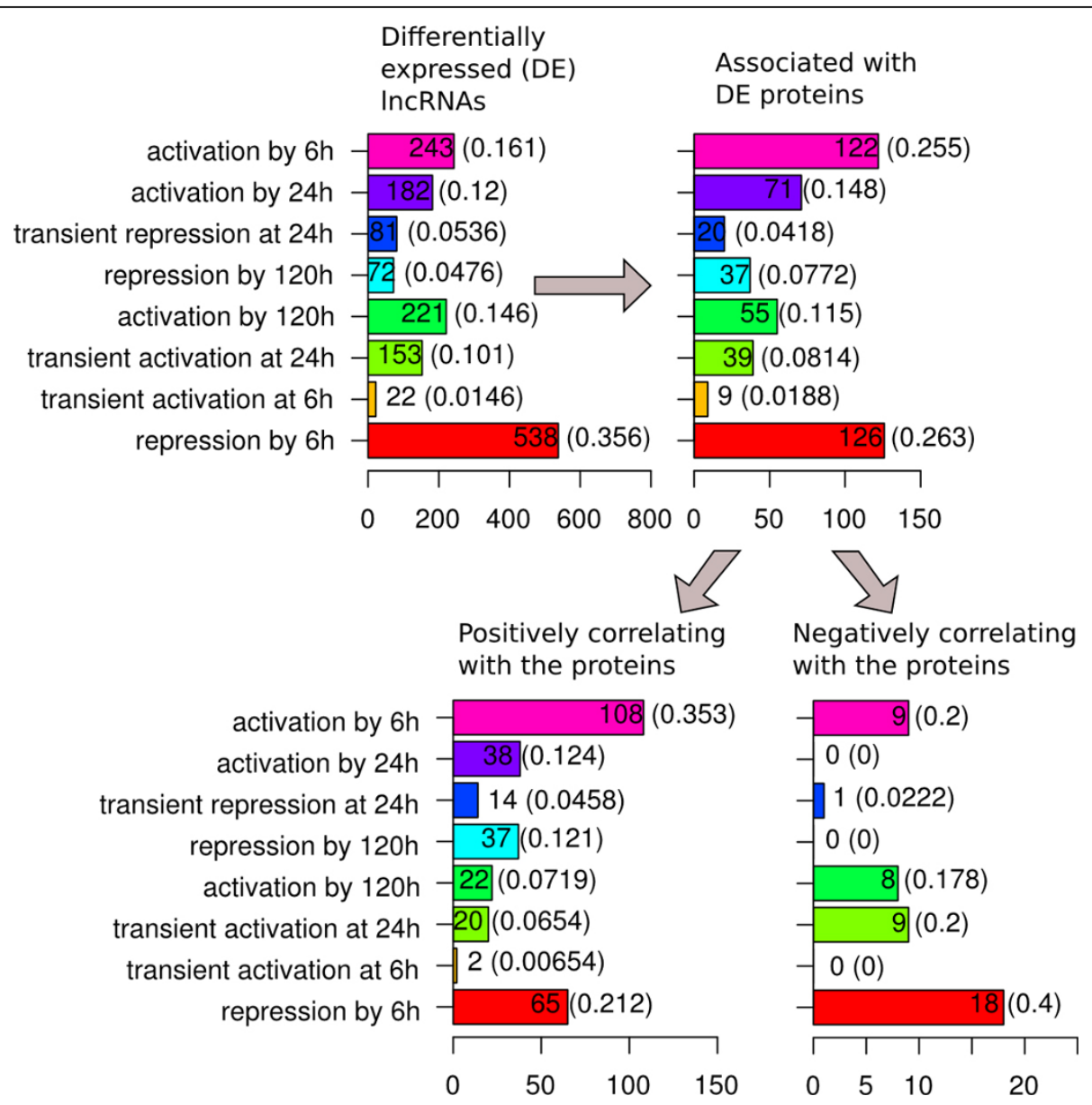

Figure 6 Protein-associated differentially expressed IncRNAs classified by their "expression rate" dynamic modes. Distribution of proteinassociated IncRNAs by their "expression rate" dynamic modes (see Additional File 2) in a sequence of filtration steps presented on Figure 5.

with the largest fraction increase (1.6-times) was repression by $120 \mathrm{~h}$, followed by the mode of permanent activation by $6 \mathrm{~h}$. At the same time, the fraction of lncRNAs activated by $120 \mathrm{~h}$, as well as permanently repressed by $6 \mathrm{~h}$ further decreased, 1.6- and 1.2-times, respectively.

Surprisingly, the modes with the highest increase among the positively-correlating lncRNAs were strongly under-represented among the negatively correlating lncRNAs and vice-versa. As such, for the negatively correlating lncRNAs, the fraction of lncRNAs activated by $120 \mathrm{~h}$ increased 1.6-times, and those permanently repressed by $6 \mathrm{~h}$ increased 1.5-times. On the contrary, the fraction of lncRNAs permanently activated by $6 \mathrm{~h}$ decreased 1.3-times, while lncRNAs activated by $24 \mathrm{~h}$ were completely absent. Also, the frequency of lncRNAs transiently activated at $24 \mathrm{~h}$ increased 2.5-times.

Analysis of the "magnitude" modes confirmed and further clarified the dynamic patterns described above (Figure 7). Among all differentially expressed lncRNAs the most frequent modes were "decreased expression by
$6 \mathrm{~h}$ " (46\%) and "increased expression by $120 \mathrm{~h}$ " (22\%). Overall, protein-associated differentially expressed lncRNAs revealed an increase in the increased-expression modes: upregulation by $24 \mathrm{~h}$ (1.7-times increase in fraction), upregulation by $6 \mathrm{~h}$ (1.4-times increase), transiently upregulated during 6-24 h (1.4-times increase), upregulation by $120 \mathrm{~h}$ (1.2-times increase). On the contrary, a reduction in the fraction of decreased expression modes was observed. The most notable was a 1.4-times decrease for the lncRNAs with down regulation by $6 \mathrm{~h}$ and by $120 \mathrm{~h}$. Except for the lncRNAs with decreased expression by $120 \mathrm{~h}$, the distribution of "magnitude" modes in general reflected the distribution of the "rate" modes.

Similarly, when the differentially expressed lncRNAs positively correlating with their associated protein coding genes were compared with those of all the protein coding gene-associated differentially expressed lncRNAs, a further rise in the fraction of the increased-expression modes was observed. Namely, for the fractions of lncRNAs with 


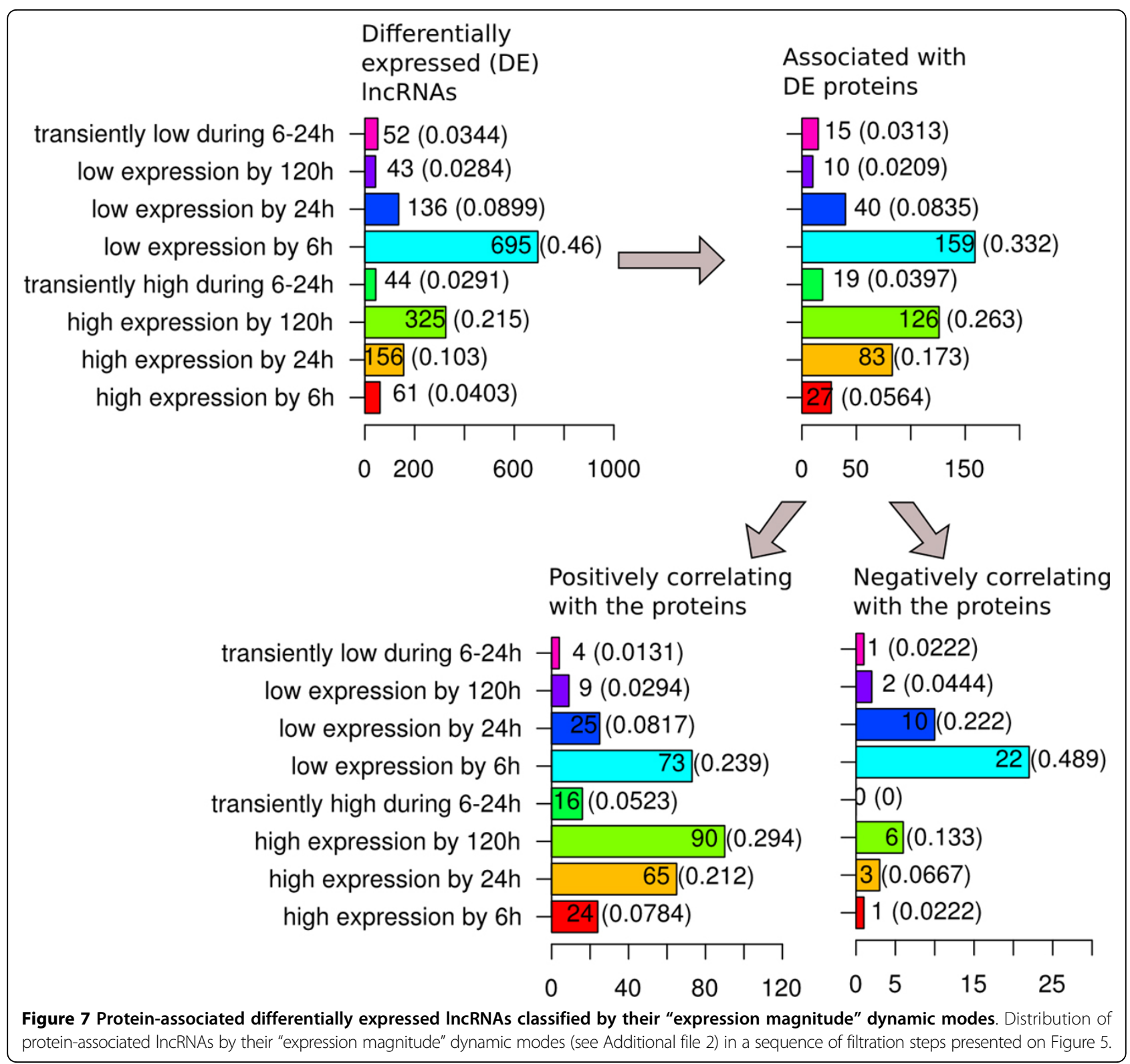

increased expression by $6 \mathrm{~h}, 24 \mathrm{~h}$ and $120 \mathrm{~h}$ the increase was 1.4-, 1.2- and 1.1-times, respectively. The fraction of lncRNAs with transiently increased expression between 6 $\mathrm{h}$ and $24 \mathrm{~h}$ increased 1.3-times. At the same time, for most of the downregulated expression modes a decrease in their fraction among the positively correlating lncRNAs was observed. The only exception were lncRNAs with decreased expression by $120 \mathrm{~h}$. Their fraction increased 1.4-times. For lncRNAs positively correlating with their associated protein coding genes, compared to all differentially expressed lncRNAs, the frequency of transcripts activated by $6 \mathrm{~h}$ increased 2.2-times, while the frequency of transcripts activated by $120 \mathrm{~h}$ and $24 \mathrm{~h}$ decreased 2.0 - and 1.6-times, respectively. The opposite was observed for the repressed lncRNAs. The fraction of lncRNAs repressed by $6 \mathrm{~h}$ decreased 1.7-times, while the fraction of lncRNAs repressed by $120 \mathrm{~h}$ increased 2.5-times. See Additional files 3, 4, 5, 6 for more details.

Since the listed differences were strongly statistically significant, the results suggest that GA is linked with lncRNAs positive correlation with the protein coding gene counterparts if the former are induced, or negative correlation if the former are repressed. We also observed that early induced $(6 \mathrm{~h})$ lncRNAs tend to be positively correlating with the associated protein coding genes, linked with their induction, while late induction of the lncRNAs more often occurs for lncRNAs negatively correlating with the associated protein coding genes, linked with their repression. 
GO analysis revealed that the positively correlating gene pairs activated by $6 \mathrm{~h}$ were significantly enriched in muscle development genes $\left(P=6.96 \cdot 10^{-3}\right)$, represented by the HOX (HOXC4, HOXC6, HOXD3, and HOXD8) and PDLIM (PDLIM5, PDLIM7) family members, phosphoprotein phoshpatases (DUSP16, NCAM2), and a transcription repressor TMF1 (Figure 8). Three of these genes (TMF1, PDLIM5, PDLIM7) were also associated with actin cytoskeleton. This GO category was significantly enriched among the $6 \mathrm{~h}$-activated positively correlating gene pairs $\left(P=3.61 \cdot 10^{-2}\right)$. Two annotated protein-coding genes associated with negatively correlating lncRNAs transiently repressed at $24 \mathrm{~h}$, were PURA and POLR2F. It resulted in a significant gene enrichment for general transcription from RNA polymerase II promoter GO $\left(P=7.39 \cdot 10^{-3}\right)$ for this group of genes. LncRNA genes exhibiting repressive expression rate modes did not reveal any significant GOs (See Figure 9 for their heatmaps, along with the ones of the associated positively correlating proteins).

When differential expression was considered regardless the significance of correlation, significant GOs were obsereved for a few more expression patterns. The results below describe the ontologies of protein-coding genes associated with a given type of dynamics of their lncRNA coding neighbors. Analysis of expression rate and magnitude modes demonstrated several waves of functionally specialized lncRNA gene expression. The first wave (0-6 h after RA treatment) permanently activated housekeeping (metabolism, DNA repair, splicing, translation) and nonHOX transcription factor genes. The second wave (24 h) transiently activated genes specific to actin cytoskeleton, nervous system development (including HOX transcription factors), and PDGF pathway. The third wave, visible at $120 \mathrm{~h}$ time point, activated genes involved in cell-cell signalling, cation transport, sensory perception, Beta3 adrenergic receptors pathway, Slit/Robo-mediated axon guidance pathway, EGF pathway, integrin signalling, adrelalin biosynthesis and angiogenesis (see details on the GO analysis of dymanic patterns in Section 1.2 of Additional file 1).

All the above associations between gene co-localization and the dynamics of transcription do not have a simple interpretation. Therefore we further investigated the distribution of dynamic modes for each individual GA class. LncRNAs significantly correlating with their associated protein coding genes were compared against the nonsignificantly correlating ones.

\section{Association between GAs and expression dynamics}

In the view of the above observations, modes of rapid $(6 \mathrm{~h})$ and delayed $(120 \mathrm{~h})$ up- and down-regulation of lncRNAs were of a particular interest. Among the lncRNAs activated by $6 \mathrm{~h}$, intergenic transcripts represented two thirds of negatively correlating lncRNAs (Figure 10A). For the positively correlating lncRNAs this GA class, although abundant, was less frequent than intronic GA (38\% vs. $43 \%)$. At the same time, among the lncRNAs repressed by $6 \mathrm{~h}$ the fractions of intergenic and intronic transcripts were not equal for both positively and negatively correlating lncRNAs (Figure 10C). A different picture was observed for lncRNAs activated and repressed by $120 \mathrm{~h}$. Only positively correlating repressed lncRNAs were characterized with intronic transcripts as the dominant GA class. It represented $68 \%$ of positively correlating repressed lncRNAs versus $36 \%$ among the induced lncRNAs (Figure 10B and 10D).

Remarkably, lncRNAs co-localized with associated proteins in $5 \mathrm{kbp}$-distant bidirectional promoters, as well as in upstream and downstream intergenic regions, were significantly associated with rapid induction, but not rapid repression (Figure 11A). Most of them positively correlated with the associated protein coding genes (Figure 10A). However, the effect of such induction was rather long term (Additional file 6). At the same time, for lncRNAs localized within $10 \mathrm{kbp}$ from the protein coding genes in bidirectional promoters and downstream intergenic regions, rapid repression was a more common mode. Although the distribution of dynamic modes in correlating protein-associated lncRNAs at $5 \mathrm{kbp}$ and $10 \mathrm{kbp}$ distances in bidirectional promoters and upstream regions was biased towards rapid activation, the majority of rapidly activated and repressed proximal (1 kbp-distant) lncRNAs were equally represented in these GA classes (Figures 11A and 11B). For intergenic downstream lncRNAs a similar tendency was observed. Moreover, for the $1 \mathrm{kbp}$-distant lncRNAs of this GA class the bias was shifted towards rapid repression with ratio 9:4 (Figure 11C). Notably, among lncRNAs encoded within $5 \mathrm{kbp}$ distance from bidirectional promoters, the bias towards increased expression by $24 \mathrm{~h}$ and, especially, $120 \mathrm{~h}$ was evident, suggesting existence of a mechanism for the rapid and prolonged activation in the cells.

A clear difference was also observed between intronic sense and intronic antisense lncRNAs. While for the former rapid activation and induction were equally represented, the latter revealed a 14:1 bias towards rapid repression (Figure 11D). For intronic antisense GA the number of lncRNAs activated by $120 \mathrm{~h}$ was 5.5 -times higher than this number forthe repressedgenes. Among the lncRNAs positively correlating with the associated protein coding genes an opposite bias for delayed regulation was observed. The number of lncRNAs repressed by $120 \mathrm{~h}$ was 3.1-times higher than that activated by $120 \mathrm{~h}$ (Figures 10B and 10D), although the number of up- and 


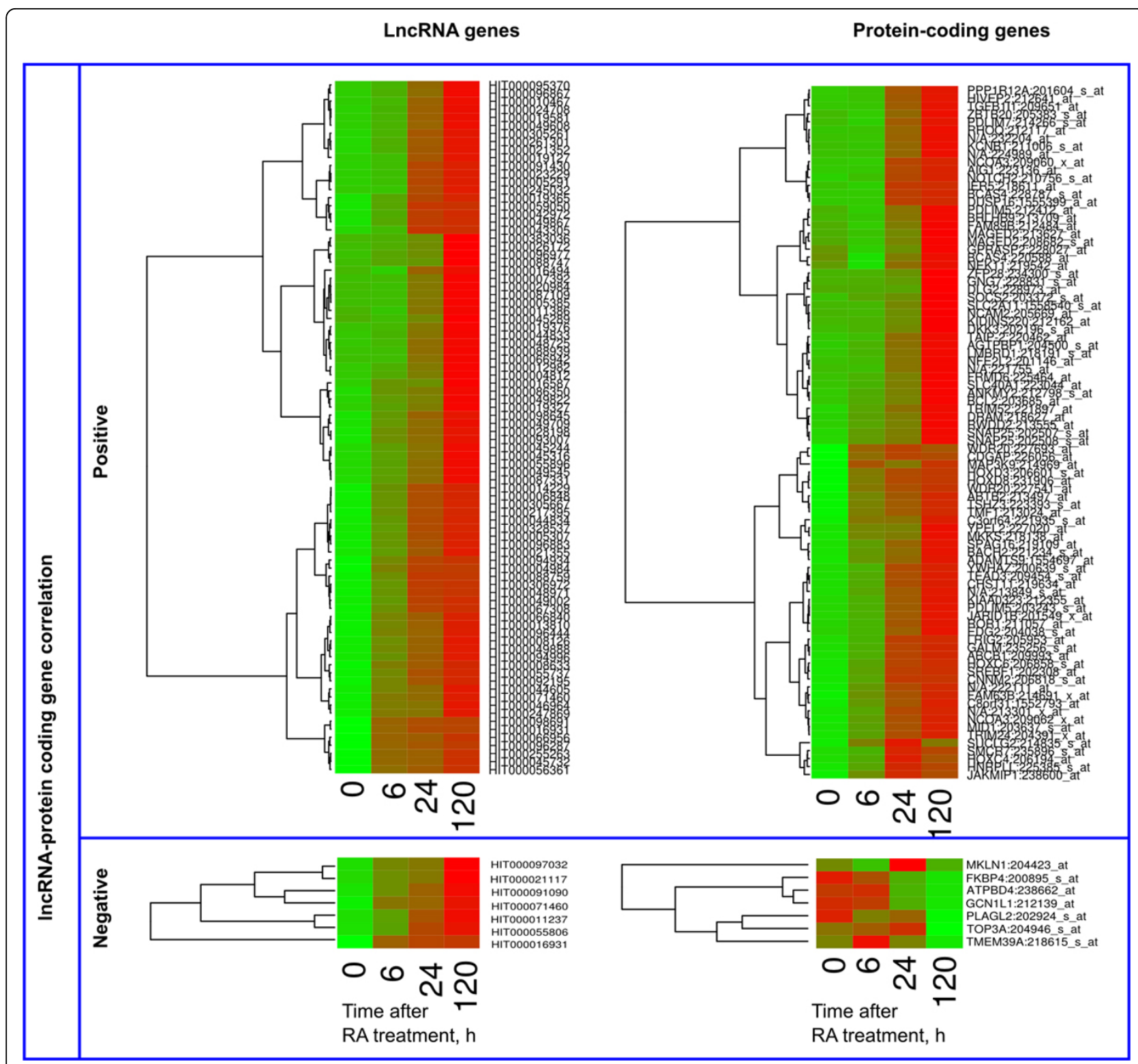

Figure 8 Cluster diagrams of IncRNA genes activated by $\mathbf{6 h}$ and their associated protein coding genes. Only significantly correlating LncRNA - protein gene pairs are presented. Expression values z-score of individual genes was used to generate the heatmaps. LncRNA and protein coding genes are ordered independently, according to their clustering.

downregulated lncRNAs by this time point was comparable and predominant relatively to the rapid activation modes.

Provided that the majority of intronic antisense lncRNAs had decreased expression level already by $6 \mathrm{~h}$, the results are likely to reflect a slow activation mechanism of lncRNAs not correlating with their associated protein coding genes. At the same time, slowly repressed, rapidly activated and rapidly repressed intronic lncRNAs were mainly positively correlating with their associated protein coding genes. See Additional files 7, 8, 9, 10 for more details.

\section{Validation of microarray data using qRT-PCR}

Quantitative RT-PCR (qRT-PCR) was utilized to validate the correlation patterns of lncRNA-protein coding gene pairs obtained with microarrays. For the validation experiments, we selected five positively and five negatively correlating gene pairs. They represented the following major GA classes: intronic sense, intronic antisense, intergenic, antisense and bidirectional. QRT-PCR data for all the gene pairs were concordant with the corresponding microarray data (Figure 12). 


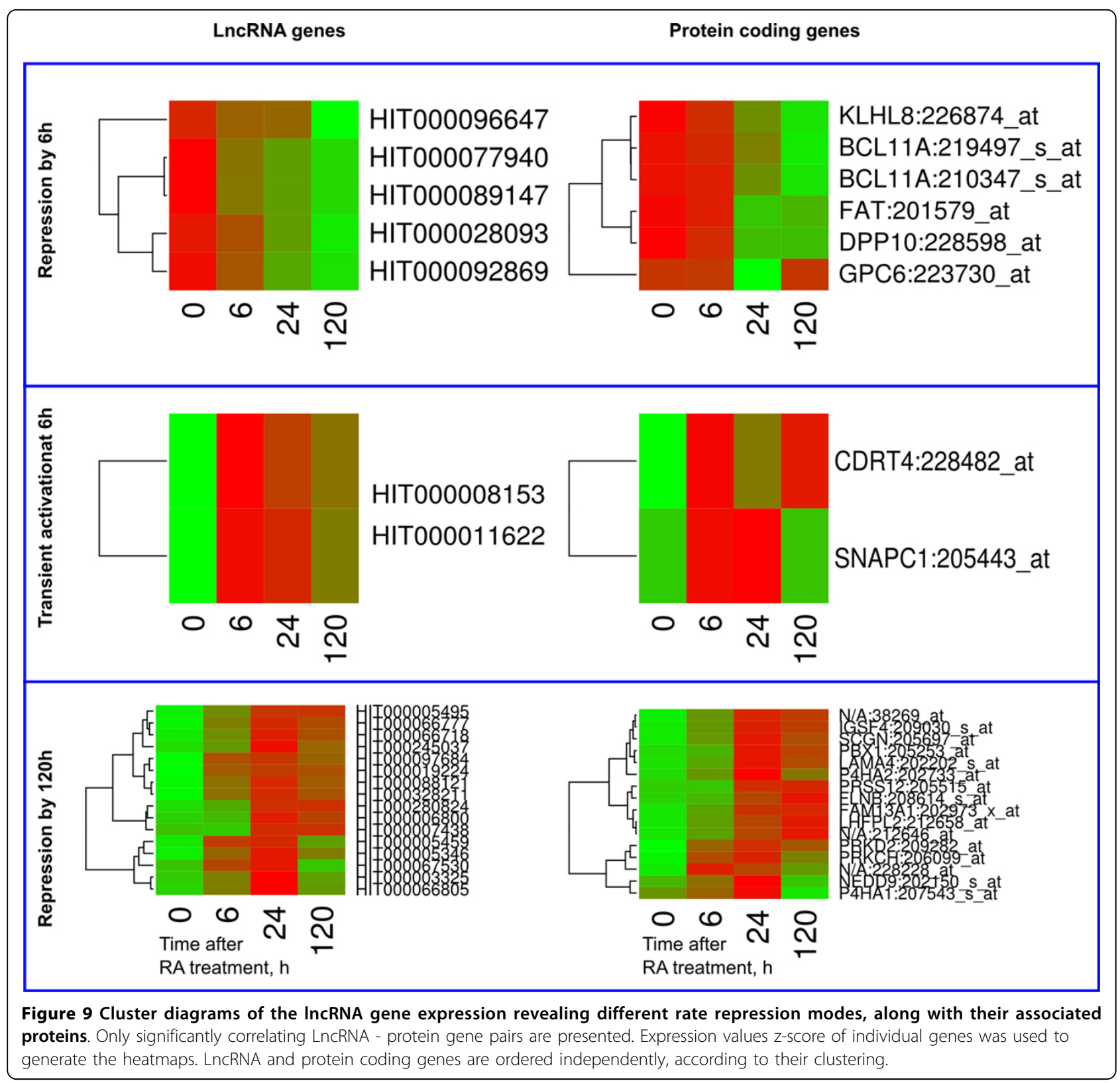

\section{Discussion}

In previous studies focusing on the analysis of dynamics of lncRNA expression only four or less architecture classes have been considered. The first study describing genome-wide dynamics of lncRNA expression was published by Ravasi and colleagues in 2006 [27]. Activation of mouse macrophages with LPS led to upregulation of 53 and downregulation of 17 lncRNAs. Several of these transcripts were encoded on the opposite strand of protein-coding genes. Time-course analysis of the activation response revealed no consistent pattern in the expression dynamics of these sense-antisense gene pairs [27]. In a later work, the idea of coordinated regulation of co-localized lncRNA-protein coding gene pairs was tested in a study involving 11 time points of a 16-day course of differentiation of embryoid bodies [6]. The lncRNA-protein coding gene pairs were classified into three categories by their genomic architecture: cis-antisense, bidirectional promoter-associated and intronic. Using Pearson's correlation analysis, the study demonstrated that bidirectional and intronic-associated, but not cis-antisense classes of transcript pairs tend to correlate positively. Interestingly, their randomized controls demonstrated a strong bias towards positive correlation coefficients in cis-antisense pairs and negative correlation for intronic and bidirectional architectures. At the 
A)

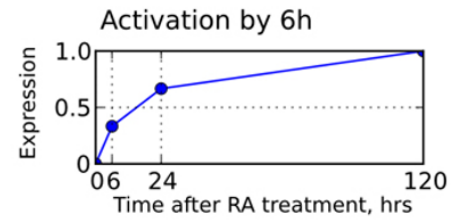

Genomic Correlating with the associated proteins architecture

promoter-associated -12 intergenic -

bi-directional antisense -7 3 intronic

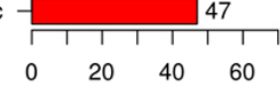
Positive

2 16

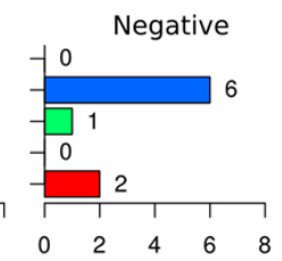

C)
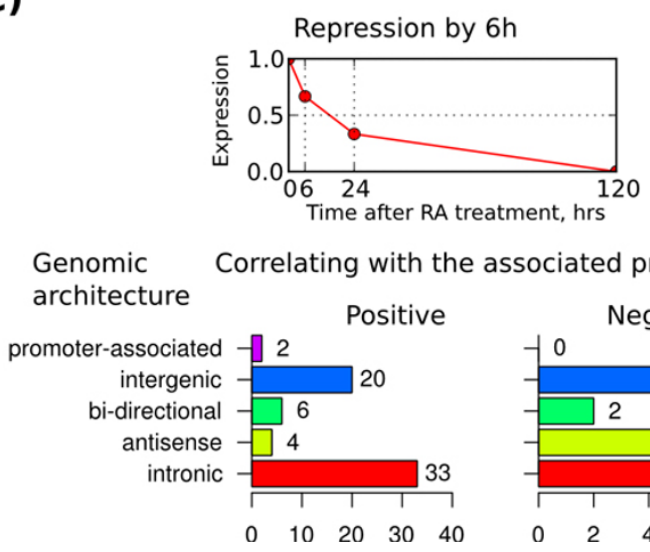

B)
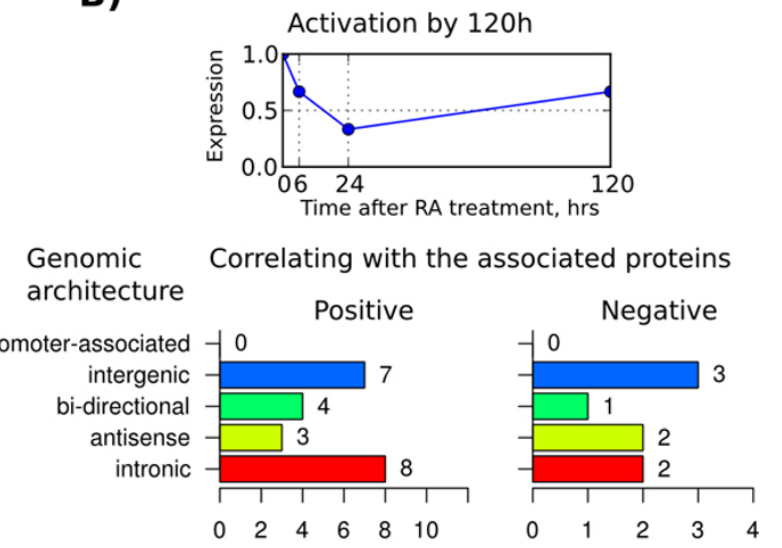

D)
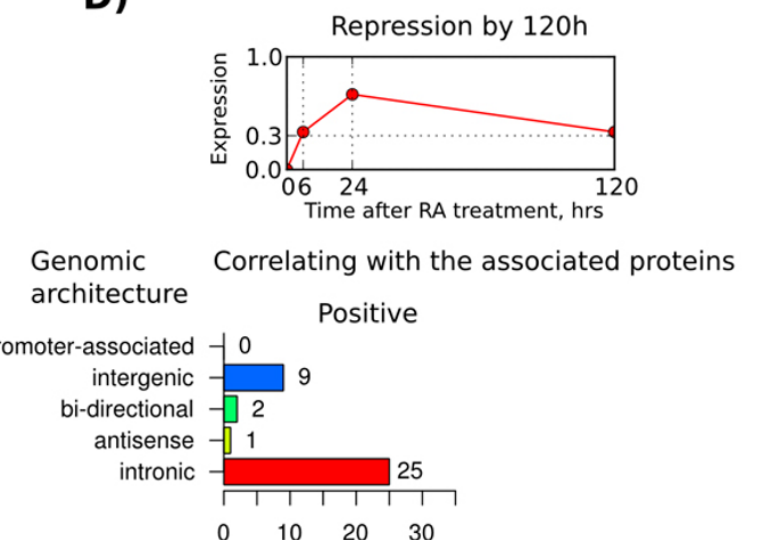

Figure 10 Distribution of genomic architecture super-classes among IncRNAs of selected dynamic modes. For IncRNAs, which expression dynamic modes revealed the strongest association with expression of their co-localized protein counterparts, the distribution of genomic architecture super-classes is shown. Four dynamic modes are shown on panels A-D. Each panel includes a schematic representation of the temporal pattern of the dynamic mode (top) and their genomic architecture super-class distribution for IncRNAs positively (bottom-left) and negatively (bottom-right) correlating with their associated proteins, all differentially expressed during RA-induced differentiation of neuroblastoma cells.

same time, existence of both positively and negatively correlating examples of lncRNA-protein coding gene pairs was noted.

Our study confirms the previous observations in that intronic and bidirectional gene pairs tend to correlate positively. A detailed analysis of genomic architecture allowed us for the first time to demonstrate that lncRNAs in downstream-associated orientations towards protein coding genes tend to correlate negatively with the protein coding genes, while intronic antisense transcripts were equally represented as positively and negatively correlating (Figure 5). A detailed analysis of expression dynamics revealed that intronic transcripts more often postitively correlate with their paired protein coding transcripts when repression of the former is observed (Figures 10C, Figure 10D and Figure 11D). At the same time, positive correlation is predominantly observed for intronic lncRNAs with rapid ( $6 \mathrm{~h}$ post-induction), but not slow (120 $\mathrm{h}$ post-induction) activation.
The microarray array results gene pairs representative of all major GAs have been successfully validated by qRTPCR. Our data indicate that intergenic lncRNA BC030713, encoded in the HOXD gene cluster between HOXD3 and $H O X D 1$, was highly induced and positively correlated with HOXD3 expression. HOXD is one of the four HOX clusters of genes that are essential for embryonic development. These clusters are characterized by extensive network of IncRNA expression [28] with a concordant expression of lncRNAsand HOXgenes. Interestingly, individual induction of several HOXD genes was sufficient to induce both growth arrest and neuronal differentiation, which is associated with downregulation of cell cycle-promoting genes and upregulation of neuronal differentiation genes [29]. The concordant expression of lncRNAs and HOX genes was also reported for the HOXA cluster during RA-induced differentiation of teratocarcinoma cell line [30] and for $H O X B$ cluster during mouse embryonic stem cell differentiation [6]. Such co-regulated expressions may reflect 
shared regulatory elements of transcription or could be due to regulatory activity of lncRNA controlling the neighbouring genes. The transcriptional activity of $H O X$ genes is highly dependent on chromatin modifications, such as active chromatin associated histone H3K4 trimethylation (H3K4me3) or repressing H3K27 trimethylation (H3K27me3) [31]. Indeed, the common regulatory theme of IncRNA-mediated control of $H O X$ genes is 


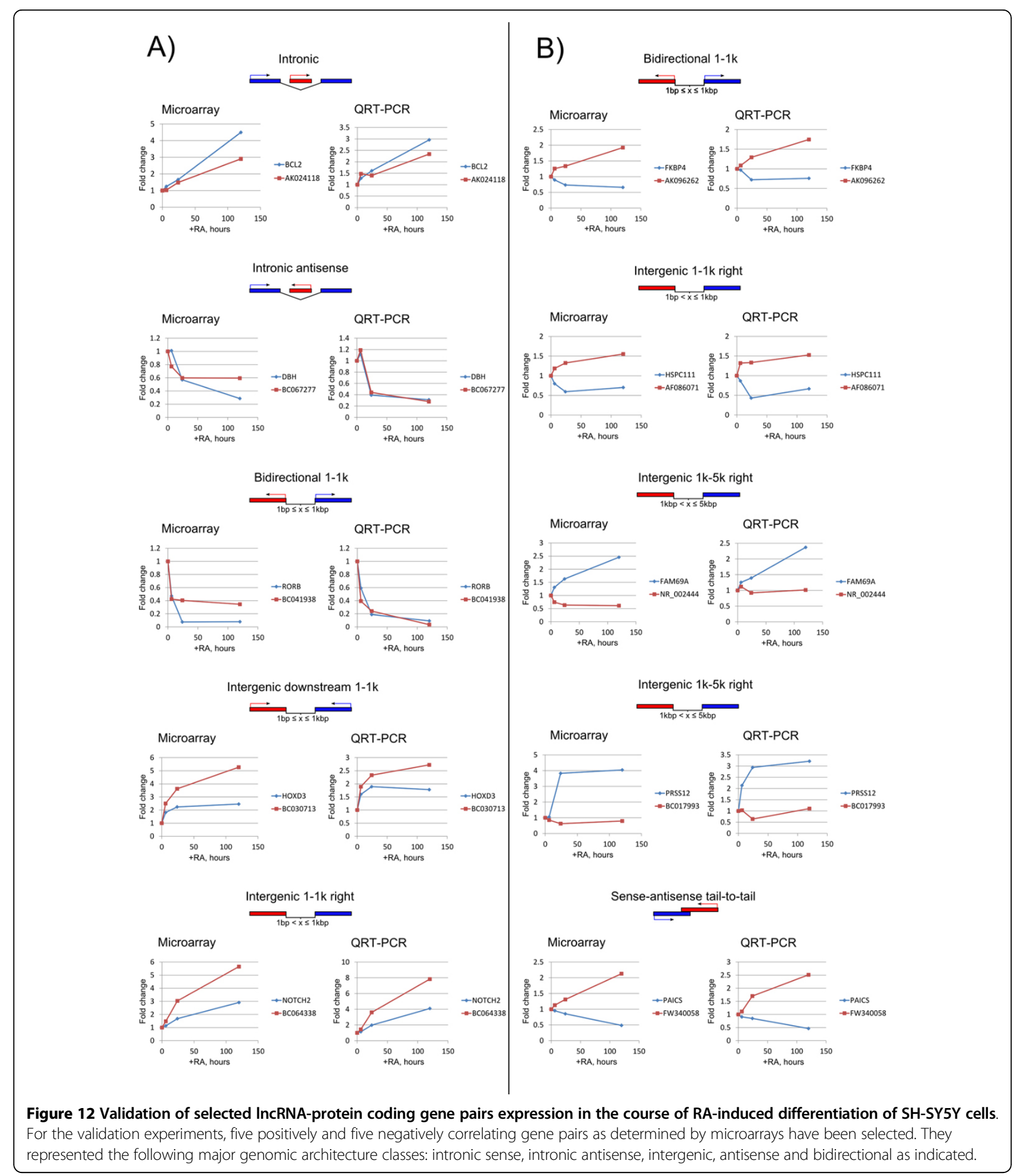

recruitment of chromatin modifying complexes catalyzing these modifications, such as cis-activation of $H O X A$ cluster by HOTTIP IncRNA-mediated recruitment of WDR5/MLL complex causing H3K4me3 modification [32], or trans-repression of $H O X D$ genes by HOTAIR lncRNA recruiting PRC2 complex that imposes H3K27me3 mark [33].

Regarding the antisense GA, a comparable number of cases of positively and negatively correlating gene pairs were observed (Figure 5). Therefore, it is possible that 
both positive [34-36] and negative [37-39] regulatory mechanisms may act in such cases. Currently, the postive regulatory role of antisense transcripts is more favored in the scientific community. However, here we report a validated case of negative correlation of FW340058 lncRNA with the transcript of its tail-to-tail antisense proteincoding neighbor PAICS (Figure 12). PAICS catalyzes steps 6 and 7 of purine biosynthesis required for proliferation of cancer cells. PAICS is activated in many cancer types [40]. Arrest of neuroblastoma cells proliferation is preceded their differentiation.

In our study we noticed an unusual case of lncRNA AK096262 sharing a bidirectional promoter with FKBP4 protein-coding gene and negatively correlating with its transcription (Figure 12). The ligand of FKBP4, FK506 was shown to stimulate neuronal differentiation and induce the rapid regeneration of hippocampal neurons [41]. It is usually assumed that transcription of genes from bidirectional promoters correlates positively. Indeed, such antiregulated expression of genes, as negatively correlating $A K 096262-F K B P 4$ gene pair is relatively rare in the human genome accounting for only $11 \%$ of cases [42]. This negative correlation may reflect the cis-regulatory effect of AK096262 on FKBP4 transcription, as has been reported for promoter associated lncRNAs targeting PRC2 complex that causes repressive histone trimethylation (H3K27me3) [43] for targeting inhibitors of activating histone deacetylases on the promoter of cyclin D1 gene [22]. An alternative model of inhibition of coding gene by non-coding transcription from bidirectional promoter is via the competition for the same pool of general transcription factors as was described for cryptic unstable transcripts (CUTs) regulating TPI1 gene expression in the yeast [44]. In this case the act of transcription is important per se rather than the functional activity of the transcription product.

Detailed GO analysis revealed that lncRNA genes have a tendency to co-localize with protein-coding genes having specific biological functions, such as embryonic development and cytoskeleton reorganization (see Additional file 1 Section 1.1). Moreover, these functional associations were specific for certain GA classes. By analyzing the dynamics of differentially expressed lncRNAs and their associated genes we found that these functions are realized by the cells via at least three gene expression waves. The first wave activated genes with housekeeping functions. The second wave was characterized by activation of homeotic transcription factors, PDGF pathway and actin cytoskeleton-related genes. Genes activated during the third wave encoded receptors, metabolism and signalling pathways specific to neural cells. The coordinated waves of gene expression have been reported for protein coding genes during neuronal differentiation of embryonic stem cells [45]. Our study is the first demonstration of such waves for lncRNA genes.

In sum, in the present paper we dissected a global picture of correlating expression between lncRNAs and their neighboring protein-coding genes. We provided a detailed analysis of genome architecture, which we regard as an active player in regulation of transcription. Working hypotheses regarding particular systemic mechanisms bridging together coding and noncoding parts of the genome to regulate cellular differentiation have been formulated. Future studies will be dedicated to their exprerimental testing.

\section{Conclusions}

This is the first report detailing dynamical changes of multiple lncRNAs during RA-induced neuroblastoma differentiation. Integration of genomic and transcriptomic levels of information allowed us to demonstrate specific behavior of lncRNAs organized in different GAs. This study also provides a list of lncRNAs with possible roles in neuroblastoma.

\section{Methods}

\section{Cell cultures}

SH-SY5Y cell line was purchased from American Type Culture Collection (ATCC ${ }^{\circledR}$ CRL-2266 ${ }^{\mathrm{TM}}$ ). SH-SY5Y cells were cultured in Ham's F12 DMEM supplemented with $10 \% \mathrm{FBS}$ in a humidified incubator at $37^{\circ} \mathrm{C}$ with $5 \% \mathrm{CO}_{2}$. For cell differentiation experiment SH-SY5Y cells were plated onto laminin coated dishes and on the next day were induced to differentiate by addition of $10 \mu M$ alltrans-retinoic acid (RA, Sigma).

\section{Custom microarray chip}

Custom microarray (Agilent) was designed to measure expression of putative IncRNA transcripts annotated in $\mathrm{H}$-Invitational database. 11,564 probes were designed to match a 60nt sequence at the 3'-end of the transcripts (see the full list in Additional file 11). The chip also included 42 quality control probes and 728 probes matching 446 protein-coding genes for cross-chip quality control. Total RNA from SH-SY5Y cell lysates was purified using RiboPure $^{\mathrm{TM}}$ kit (Ambion/Life Technologies) according to the manufacturer's instructions. The quality of total RNA was assessed using an Agilent 2100 Bioanalyzer (Agilent Technologies) RNA samples were sent to DNA Chip Research Inc. (Yokohama, Japan) for hybridization.

\section{qRT-PCR validation}

Total RNA was used as a template for reverse transcription using QuantiTect Reverse Transcription Kit (Qiagen) using random hexamer primers. The transcript levels were analyzed by qPCR run on Rotor-Gene Q 
machine using Rotor-Gene SYBR Green PCR Kit (Qiagen). The primers used throughout our study are listed in Additional file 12.

Computational analysis

\section{Probe filtering pipeline}

From the list of probes, 12,173 non-redundant sequences have been selected. The sequences were scanned across human mRNA database (UCSC refMrna, 11 Oct 09) with NCBI BLAST allowing non-gapped alignments of $95 \%$ identity with no more than 1 mismatch. Thus, each of remaining 12,132 probes uniquely matched at least one mRNA sequence. 1,825 probes matching reverse-complementary sequences of mRNA transcripts were excluded from the analysis. Alignment of the remaining 10,307 probes with known RNA sequences (UCSC, all_mRNA and refSeqAli tables, excluding random chromosomes and haplotypes) selected 10,177 transcripts. 289 probes were removed as duplicated in their mRNA sequences. Probes matching protein-coding RNAs were excluded by the presence of the latter in refGene database (UCSC, Oct 09) or by sharing a strong sequence similarity with any known protein-coding RNAs (assessed with CRITICA software). The remaining 7,926 probes matching 9,267 non-coding transcripts were thus selected for further analysis. They were classified into 19 classes by the architecture of their genes in respect to their localization relative to their nearest protein-coding genes. A more general classification into 5 super-classes (intronic, promoter-associated, intergenic, bidirectional and antisense) was further derived by combining topologically similar architecture classes.

Architecture distribution was analyzed in a sequence of transcript filtration steps: 1) all lncRNAs present on the custom microarray, 2) lncRNAs differentially expressed (differentially expressed) in neuroblastoma differentiation course, 3) differentially expressed lncRNAs associated with any proteins, 4) differentially expressed lncRNAs associated with differentially expressed proteins, 5) differentially expressed lncRNAs positively or negatively correlating with their associated differentially expressed protein counterparts (listed in Additional files 13 and 14, respectively).

\section{Statistical analysis}

By comparing the lncRNA distribution changes between each two of the sequential steps of filtration significantly over- and under-represented lncRNA GAs and dynamical modes were identified. Statistical significance of each individual class was assessed by hypergeometric test of the difference between its frequency among the lncRNAs left after a given filtration step versus the class frequency among the lncRNAs removed by the filtration. The frequencies were tabulated in two ways: 1) all members of a given class versus all non-members; 2) all members of a given class versus all members of another class. Thus two null-hypotheses of the frequency bias in lncRNAs was tested: 1) the frequency of a given class was not affected by the filtration procedure; 2) the frequency of a given class was not affected relative to the frequency of another particular class.

To remove the bias in the $\mathrm{P}$-values resulting from multiple comparisons Bonferroni correction was applied.

\section{Analysis of gene expression}

LncRNA expression in neuroblastoma cells was measured with the microarray at 4 time points $(0,6,24$ and 120 hours) following RA-induced differentiation. The experiment was repeated in two biological replicates. Fold change between the first and the last time point and Kendall's correlation coefficient were chosen as measures of differential expression and concordance. A gene was classified as differentially expressed if its expression in two biological replicates was concordant in any three of the four time points (Kendall's $\tau>0.6$ ) and the fold change was not less than 1.5.

Classification of expression profiles into eight dynamical modes was performed in two ways. "Expression rate" modes the difference between the median sample expression value at a given time point was calculated relative to the previous time point, the magnitude of the rate was ignored, and the sign of the rate was considered. Thus each mode represented the sign of the rate of expression change between two sequential time points. Thus, for the four studied time points the eight modes were identified as all eight possible combinations of the rate signs between them (Additional file 2, panel A). The "magnitude modes" were defined as eight combinations of values 0 (low) and 1 (high) at the four time points of the experiment (Additional file 2, panel B). To classify a given gene expression timecourse by the modes Pearson's correlation coefficients between the expression values and each mode were calculated and the mode with the highest correlation was selected as the representative.

Initially, we attempted two normalization methods applicable for both Agilent and Affymetrix array types analyzed in our studies: i) RMA background correction [46] followed by quantile normalization with [47]. and ii) normalization by ACTB gene expression values. Due to the low number of replicates, use of both methods resulted in a notable artifacts. Therefore, to ensure the robustness of our results, we skipped the normalization procedure. Since the computational methods applied to analysis of gene expression are based on correlation measures, it does not result in false positive results.

\section{Gene ontology analysis}

The functional classification of lncRNA genes was inferred from the available information on the GOs of the associated protein-coding genes. GO over-representation analysis was 
carried out using PANTHER database [48]. The P-values were calculated according to the binomial test integrated in the PANTHER online tool. Bonferroni's corrections for multiple testing was applied, followed by assessment of the GO significance at P-value cutoff level 0.05 .

\section{Additional material}

\section{Additional file 1: Supplementary results}

Additional file 2: List of rate (A) and magnitude (B) modes discriminated in the present study.

Additional file 3: Distribution of IncRNA genomic architecture classes by rate dynamic modes.

Additional file 4: Distribution of IncRNA genomic architecture classes by magnitude dynamic modes.

Additional file 5: Distribution of IncRNA combined genomic architecture classes by rate dynamic modes for IncRNAs significantly correlating with associated differentially expressed proteins. Note: absence of subfigures for certain IncRNA groups indicates insufficient statistics.

Additional file 6: Distribution of IncRNA combined genomic architecture classes by magnitude dynamic modes for IncRNAs significantly correlating with associated differentially expressed proteins. Note: absence of subfigures for certain IncRNA groups indicates insufficient statistics.

Additional file 7: Distribution of IncRNA magnitude dynamic modes by combined genomic architecture classes for IncRNAs significantly correlating with associated differentially expressed proteins. Note: absence of subfigures for certain IncRNA groups indicates insufficient statistics.

Additional file 8: Distribution of IncRNA rate dynamic modes by genomic architecture classes for IncRNAs significantly correlating with associated differentially expressed proteins. Note: absence of subfigures for certain IncRNA groups indicates insufficient statistics.

Additional file 9: Distribution of IncRNA magnitude dynamic modes by genomic architecture classes for IncRNAs significantly correlating with associated differentially expressed proteins. Note: absence of subfigures for certain IncRNA groups indicates insufficient statistics.

Additional file 10: Distribution of IncRNA rate dynamic modes by combined genomic architecture classes for IncRNAs significantly correlating with associated differentially expressed proteins. Note: absence of subfigures for certain IncRNA groups indicates insufficient statistics.

Additional file 11: List of Agilent microarray probes.

Additional file 12: List of primers used for validation studies with quantitative PCR.

Additional file 13: List of IncRNAs in complex gene architecture positively correlating with their co-localized proteins.

Additional file 14: List of IncRNAs in complex gene architecture negatively correlating with their co-localized proteins.

List of abbreviations used

IncRNA: long noncoding RNA; GA: genomic architecture; FE: fold enrichment; RA: retinoic acid.

\section{Competing interests}

The authors declare that they have no competing interests.

\section{Authors' contributions}

IVK conceived the project. AB, PJ and YN carried out bioinformatics and computational work. AY and JZT obtained all of the experimental data. IVK contributed to data analysis and interpretation. $A B$ and $A Y$ wrote the manuscript. All authors read and approved the final manuscript.

\section{Acknowledgements}

We would like to thank Yoshiyuki Sakaki and Tadayuki Takeda for support in the initial stages of this project and Kunihiko Takamatsu for advice in design of the custom microarray chip.

\section{Declarations}

Publication of this article was funded by Bioinformatics Institute, Agency for Science, Technology and Research (A*STAR), Singapore.

This article has been published as part of BMC Systems Biology Volume 7 Supplement 2, 2013: Twelfth International Conference on Bioinformatics (InCoB2013): Bioinformatics. The full contents of the supplement are available online at http://www.biomedcentral.com/bmcsystbiol/supplements/ 7/S3.

\section{Authors' details}

'Department of Genome and Gene Expression Data Analysis, Bioinformatics Institute, 30 Biopolis Str, Singapore, 138671. ${ }^{2}$ Laboratory for Computational and Experimental Systems Biology Group, RIKEN Genomic Sciences Centre, 1-7-22 Suehiro-cho, Tsurumi-ku, Yokohama, Kanagawa 230-0045, Japan.

Published: 16 October 2013

\section{References}

1. Okazaki Y, Furuno M, Kasukawa T, Adachi J, Bono H, Kondo S, Nikaido I, Osato N, Saito R, Suzuki H, Yamanaka I, Kiyosawa H, Yagi K, Tomaru Y, Hasegawa Y, Nogami A, Schönbach C, Gojobori T, Baldarelli R, Hill DP, Bult C, Hume DA, Quackenbush J, Schriml LM, Kanapin A, Matsuda H, Batalov S, Beisel KW, Blake JA, Bradt D, et al: Analysis of the mouse transcriptome based on functional annotation of 60,770 full-length cDNAs. Nature 2002, 420(6915):563-573.

2. Carninci P, Kasukawa T, Katayama S, Gough J, Frith MC, Maeda N, Oyama R, Ravasi T, Lenhard B, Wells C, Kodzius R, Shimokawa K, Bajic VB, Brenner SE, Batalov S, Forrest ARR, Zavolan M, Davis MJ, Wilming LG, Aidinis V, Allen JE, Ambesi-Impiombato A, Apweiler R, Aturaliya RN, Bailey TL, Bansal M, Baxter L, Beisel KW, Bersano T, Bono H, et al: The transcriptional landscape of the mammalian genome. Science 2005, 309(5740):1559-1563.

3. Lipovich $L$, Johnson $R$, Lin CY: MacroRNA underdogs in a microRNA world: evolutionary, regulatory, and biomedical significance of mammalian long non-protein-coding RNA. Biochim. Biophys. Acta 2010, 1799(9):597-615.

4. Rinn JL, Chang HY: Genome regulation by long noncoding RNAs. Annu Rev Biochem 2012, 81:145-66.

5. Mercer TR, Dinger ME, Sunkin SM, Mehler MF, Mattick JS: Specific expression of long noncoding RNAs in the mouse brain. Proc Natl Acad Sci USA 2008, 105(2):716-721.

6. Dinger ME, Amaral PP, Mercer TR, Pang KC, Bruce SJ, Gardiner BB, Askarian-Amiri ME, Ru K, Soldà G, Simons C, Sunkin SM, Crowe ML, Grimmond SM, Perkins AC, Mattick JS: Long noncoding RNAs in mouse embryonic stem cell pluripotency and differentiation. Genome Res 2008, 18(9):1433-1445.

7. Pang KC, Dinger ME, Mercer TR, Malquori L, Grimmond SM, Chen W, Mattick JS: Genome-wide identification of long noncoding RNAs in CD8+ T cells. J Immunol 2009, 182(12):7738-7748.

8. Sunwoo H, Dinger ME, Wilusz JE, Amaral PP, Mattick JS, Spector DL: MEN epsilon/beta nuclear-retained non-coding RNAs are up-regulated upon muscle differentiation and are essential components of paraspeckles. Genome Res 2009, 19(3):347-359.

9. Kretz M, Siprashvili Z, Chu C, Webster DE, Zehnder A, Qu K, Lee CS, Flockhart RJ, Groff AF, Chow J, Johnston D, Kim GE, Spitale RC, Flynn RA, Zheng GXY, Aiyer S, Raj A, Rinn JL, Chang HY, Khavari PA: Control of somatic tissue differentiation by the long non-coding RNA TINCR. Nature 2013, 493(7431):231-235.

10. Grote $P$, Wittler L, Hendrix D, Koch F, Währisch $S$, Beisaw A, Macura K, Bläss $G$, Kellis M, Werber M, Herrmann BG: The tissue-specific IncRNA Fendrr is an essential regulator of heart and body wall development in the mouse. Dev Cell 2013, 24(2):206-214.

11. Gomez JA, Wapinski OL, Yang YW, Bureau JF, Gopinath S, Monack DM, Chang HY, Brahic M, Kirkegaard K: The NeST long ncRNA controls 
microbial susceptibility and epigenetic activation of the interferon- $\gamma$ locus. Cell 2013, 152(4):743-754.

12. Gibb EA, Brown CJ, Lam WL: The functional role of long non-coding RNA in human carcinomas. Mol Cancer 2011, 10:38.

13. Kogo R, Shimamura T, Mimori K, Kawahara K, Imoto S, Sudo T, Tanaka F, Shibata K, Suzuki A, Komune S, Miyano S, Mori M: Long noncoding RNA HOTAIR regulates polycomb-dependent chromatin modification and is associated with poor prognosis in colorectal cancers. Cancer Res 2011, 71(20):6320-6326.

14. Kino T, Hurt DE, Ichijo T, Nader N, Chrousos GP: Noncoding RNA gas5 is a growth arrest- and starvation-associated repressor of the glucocorticoid receptor. Sci Signal 2010, 3(107):ra8.

15. Feng J, Bi C, Clark BS, Mady R, Shah P, Kohtz JD: The Evf-2 noncoding RNA is transcribed from the Dlx-5/6 ultraconserved region and functions as a Dlx-2 transcriptional coactivator. Genes Dev 2006, 20(11):1470-1484.

16. Carrieri C, Cimatti L, Biagioli M, Beugnet A, Zucchelli S, Fedele S, Pesce E, Ferrer I, Collavin L, Santoro C, Forrest ARR, Carninci P, Biffo S, Stupka E, Gustincich S: Long non-coding antisense RNA controls Uchl1 translation through an embedded SINEB2 repeat. Nature 2012, 491(7424):454-457.

17. Gong C, Maquat LE: InCRNAs transactivate STAU1-mediated mRNA decay by duplexing with 3' UTRs via Alu elements. Nature 2011, 470(7333):284-288

18. Engström PG, Suzuki $H$, Ninomiya N, Akalin A, Sessa L, Lavorgna G, Brozzi A, Luzi L, Tan SL, Yang L, Kunarso G, Ng ELC, Batalov S, Wahlestedt C, Kai C, Kawai J, Carninci P, Hayashizaki Y, Wells C, Bajic VB, Orlando V, Reid JF, Lenhard B, Lipovich L: Complex Loci in human and mouse genomes. PLoS Genet 2006, 2(4):e47.

19. Sigova AA, Mullen AC, Molinie B, Gupta S, Orlando DA, Guenther MG, Almada AE, Lin C, Sharp PA, Giallourakis CC, Young RA: Divergent transcription of long noncoding RNA/mRNA gene pairs in embryonic stem cells. Proc Natl Acad Sci USA 2013, 110(8):2876-2881.

20. Thakur N, Tiwari VK, Thomassin H, Pandey RR, Kanduri M, Göndör A, Grange T, Ohlsson R, Kanduri C: An antisense RNA regulates the bidirectional silencing property of the Kcnq1 imprinting control region. Mol Cell Biol 2004, 24(18):7855-7862.

21. Zwart R, Sleutels F, Wutz A, Schinkel AH, Barlow DP: Bidirectional action of the Igf2r imprint control element on upstream and downstream imprinted genes. Genes Dev 2001, 15(18):2361-2366.

22. Wang $X$, Arai S, Song X, Reichart D, Du K, Pascual G, Tempst P, Rosenfeld MG, Glass CK, Kurokawa R: Induced ncRNAs allosterically modify RNA-binding proteins in cis to inhibit transcription. Nature 2008, 454(7200):126-130

23. Rosenbloom KR, Dreszer TR, Pheasant $M$, Barber GP, Meyer LR, Pohl A, Raney BJ, Wang T, Hinrichs AS, Zweig AS, Fujita PA, Learned K, Rhead B, Smith KE, Kuhn RM, Karolchik D, Haussler D, Kent WJ: ENCODE wholegenome data in the UCSC Genome Browser. Nucleic Acids Res 2010, 38(Database):D620-D6255.

24. Badger JH, Olsen GJ: CRITICA: coding region identification tool invoking comparative analysis. Mol Biol Evol 1999, 16(4):512-524.

25. Grinchuk OV, Jenjaroenpun P, Orlov YL, Zhou J, Kuznetsov VA: Integrative analysis of the human cis-antisense gene pairs, miRNAs and their transcription regulation patterns. Nucleic Acids Res 2010, 38(2):534-547.

26. Nishida Y, Adati N, Ozawa R, Maeda A, Sakaki Y, Takeda T: Identification and classification of genes regulated by phosphatidylinositol 3-kinaseand TRKB-mediated signalling pathways during neuronal differentiation in two subtypes of the human neuroblastoma cell line SH-SY5Y. BMC Res Notes 2008, 1:95.

27. Ravasi T, Suzuki H, Pang KC, Katayama S, Furuno M, Okunishi R, Fukuda S, Ru K, Frith MC, Gongora MM, Grimmond SM, Hume DA, Hayashizaki Y, Mattick JS: Experimental validation of the regulated expression of large numbers of non-coding RNAs from the mouse genome. Genome Res 2006, 16:11-19.

28. Mainguy G, Koster J, Woltering J, Jansen H, Durston A: Extensive polycistronism and antisense transcription in the mammalian Hox clusters. PLOS ONE 2007, 2(4):e356.

29. Zha Y, Ding E, Yang L, Mao L, Wang X, McCarthy BA, Huang S, Ding HF: Functional dissection of HOXD cluster genes in regulation of neuroblastoma cell proliferation and differentiation. PLOS One 2012, 7(8):e40728.

30. Sessa L, Breiling A, Lavorgna G, Silvestri L, Casari G, Orlando V: Noncoding RNA synthesis and loss of Polycomb group repression accompanies the colinear activation of the human HOXA cluster. RNA 2007, 13(2):223-239.
31. Bernstein BE, Mikkelsen TS, Xie X, Kamal M, Huebert DJ, Cuff J, Fry B, Meissner A, Wernig M, Plath K, Jaenisch R, Wagschal A, Feil R, Schreiber SL, Lander ES: A bivalent chromatin structure marks key developmental genes in embryonic stem cells. Cell 2006, 125(2):315-326.

32. Wang KC, Yang YW, Liu B, Sanyal A, Corces-Zimmerman R, Chen Y, Lajoie BR, Protacio A, Flynn RA, Gupta RA, Wysocka J, Lei M, Dekker J, Helms JA, Chang HY: A long noncoding RNA maintains active chromatin to coordinate homeotic gene expression. Nature 2011, 472(7341):120-124.

33. Rinn JL, Kertesz M, Wang JK, Squazzo SL, Xu X, Brugmann SA, Goodnough LH, Helms JA, Farnham PJ, Segal E, Chang HY: Functional demarcation of active and silent chromatin domains in human HOX loci by noncoding RNAs. Cell 2007, 129(7):1311-1323.

34. Mahmoudi S, Henriksson S, Corcoran M, Méndez-Vidal C, Wiman KG, Farnebo M: Wrap53, a natural p53 antisense transcript required for p53 induction upon DNA damage. Mol Cell 2009, 33(4):462-471.

35. Kimura T, Jiang S, Nishizawa M, Yoshigai E, Hashimoto I, Nishikawa M, Okumura T, Yamada H: Stabilization of human interferon-a1 mRNA by its antisense RNA. Cell Mol Life Sci 2013, 70(8):1451-1467.

36. Johnsson P, Ackley A, Vidarsdottir L, Lui WO, Corcoran M, Grandér D, Morris KV: A pseudogene long-noncoding-RNA network regulates PTEN transcription and translation in human cells. Nat Struct Mol Biol 2013, 20(4):440-446.

37. Fish JE, Matouk CC, Yeboah E, Bevan SC, Khan M, Patil K, Ohh M, Marsden PA: Hypoxia-inducible expression of a natural cis-antisense transcript inhibits endothelial nitric-oxide synthase. J Biol Chem 2007, 282(21):15652-15666.

38. Senner $C E$, Brockdorff $N$ : Xist gene regulation at the onset of $X$ inactivation. Curr Opin Genet Dev 2009, 19(2):122-126.

39. Kraus P, Sivakamasundari V, Lim SL, Xing X, Lipovich L, Lufkin T: Making sense of DIx1 antisense RNA. Dev Biol 2013, 376(2):224-235.

40. Rhodes DR, Yu J, Shanker K, Deshpande N, Varambally R, Ghosh D, Barrette T, Pandey A, Chinnaiyan AM: Large-scale meta-analysis of cancer microarray data identifies common transcriptional profiles of neoplastic transformation and progression. Proc Natl Acad Sci USA 2004, 101(25):9309-9314.

41. Quintá $\mathrm{HR}$, Galigniana MD: The neuroregenerative mechanism mediated by the Hsp90-binding immunophilin FKBP52 resembles the early steps of neuronal differentiation. Br J Pharmacol 2012, 166(2):637-649.

42. Trinklein ND, Aldred SF, Hartman SJ, Schroeder DI, Otillar RP, Myers RM: An abundance of bidirectional promoters in the human genome. Genome Res 2004, 14:62-66.

43. Kanhere A, Viri K, Araújo CC, Rasaiyaah J, Bouwman RD, Whyte WA, Pereira CF, Brookes E, Walker K, Bell GW, Pombo A, Fisher AG, Young RA, Jenner RG: Short RNAs are transcribed from repressed polycomb target genes and interact with polycomb repressive complex-2. Mol Cell 2010, 38(5):675-688.

44. Neil H, Malabat C, d'Aubenton Carafa Y, Xu Z, Steinmetz LM, Jacquier A: Widespread bidirectional promoters are the major source of cryptic transcripts in yeast. Nature 2009, 457(7232):1038-1042.

45. Zimmer B, Kuegler PB, Baudis B, Genewsky A, Tanavde V, Koh W, Tan B, Waldmann T, Kadereit S, Leist M: Coordinated waves of gene expression during neuronal differentiation of embryonic stem cells as basis for novel approaches to developmental neurotoxicity testing. Cell Death Differ 2011, 18(3):383-395.

46. Irizarry RA, Bolstad BM, Collin F, Cope LM, Hobbs B, Speed TP: Summaries of Affymetrix GeneChip probe level data. Nucleic Acids Res 2003, 31(4):e15.

47. Bolstad BM, Irizarry RA, Astrand M, Speed TP: A comparison of normalization methods for high density oligonucleotide array data based on variance and bias. Bioinformatics 2003, 19(2):185-193.

48. Mi H, Muruganujan A, Thomas PD: PANTHER in 2013: modeling the evolution of gene function, and other gene attributes, in the context of phylogenetic trees. Nucleic Acids Res 2013, 41(Database):D377-386.

doi:10.1186/1752-0509-7-S3-S11

Cite this article as: Batagov et al: Role of genomic architecture in the expression dynamics of long noncoding RNAs during differentiation of human neuroblastoma cells. BMC Systems Biology 2013 7(Suppl 3):S11. 